\title{
Privatização da e na educação: Projetos societários em disputa
}

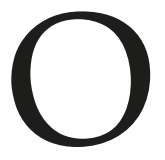

objetivo deste Dossiêé trazer subsídios aos leitores sobre o atualíssimo debate, que se refere à transformação da educação em mercadoria, negando cada vez mais seu caráter de direito básico do cidadão. Os textos aqui publicados consistem de análises acerca do avassalador crescimento da privatização $d a$ e na educação no Brasil e em outros países, particularmente na educação básica.

Esse processo de privatização coloca em risco o avanço das lutas pelos direitos humanos e colabora significativamente para a manutenção das desigualdades sociais, intensificando-se mais ou menos de acordo com a correlação de forças e com o histórico democrático e o grau da efetivação do direito à educação que se constrói em cada país. No Brasil, em que pesem os avanços ocorridos na última década e meia na materialização de direitos em políticas, recrudescem agora os processos de privatização dos e nos bens públicos, uma das estratégias centrais que propõe o capitalismo para retomar o aumento das taxas de lucro, com graves consequências para a construção efetiva dos direitos sociais e da democracia.

Na educação, a privatização acontece de múltiplas formas. Ocorre tanto por meio da oferta direta de serviços educacionais por instituições privadas, como também por meio de políticas em que o privado disputa o conteúdo das políticas públicas educativas, como é o caso das parcerias público-privadas com sistemas ou escolas, em que o setor privado, com ou sem fins lucrativos, vai assumindo o conteúdo da educação pública e mesmo a sua execução. Tais ações alinham-se especialmente às políticas de instituições como OCDE, Banco Mundial, BID, além de conglomerados internacionais privados, que concentram para isso especialistas e financiam governos na adaptação de seus projetos educacionais aos objetivos de seus investimentos. Isto ocorre na formação de professores, no monitoramento dos sistemas educativos, no patrocínio de avaliações internacionais,

* É doutora em Educação e professora da Universidade Federal do Rio Grande do Sul nos cursos de graduação e pós-graduação em Educação. É pesquisadora produtividade CNPQ. Coordena grupo de pesquisa sobre a relação entre o público e o privado na educação. Porto Alegre, RS- Brasil. E-mail: <veraperoni@gmail.com>.

* É Doutora em Educação pela Pontifícia Universidade Católica de São Paulo. Professora Titular Emérita, aposentada da Universidade Federal de Santa Catarina e Membro do corpo permanente de professores do Programa de Pós-Graduação em Educação da Universidade do Oeste de Santa Catarina. É a atual Editora da Revista Retratos da Escola (Esforce/CNTE). Florianópolis, SC- Brasil. E-mail: <lscheibe@uol.com.br>. 
entre outras ações, para as quais são estabelecidas metas a serem cumpridas que interferem tanto na gestão como no próprio currículo escolar. Exemplo significativo ocorre quando, através da privatização endógena, a gestão pública passa a ser regida pelas normas do mercado. Lembramos aqui as recentes investidas das citadas organizações para a implantação de novos modelos gerenciais nas escolas públicas, como o contrato das organizações sociais (OS) nas escolas de Goiás e o modelo de pagamento por desempenho no ensino médio da rede estadual do Ceará.

As diversas formas de privatização têm profundas consequências para a democratização da educação, cujo papel é fundamental na construção de uma sociedade mais justa e igualitária. Quando o privado assume a direção das políticas e imprime seus valores, temos grandes perdas para o processo societário em desenvolvimento, que mercantiliza o próprio conhecimento, um precioso bem público.

A expansão da privatização na educação já provoca hoje profundas consequências para o trabalho docente, desrespeitado cada vez mais na sua autonomia, quando o seu conteúdo já vem pronto, estruturado, para apenas ser ministrado. São inúmeros os sistemas públicos que compram seus programas de ensino de institutos como Unibanco e Ayrton Senna, cuja ênfase tem foco nos resultados e numa política de controle e intimidação dos docentes por meio de premiação e sanções. Conhecemos a atual recorrência na responsabilização dos professores e da sua formação pelo insucesso escolar. Importantes condições que trazem problemas para um bom aproveitamento dos ensinamentos escolares, tais como a pobreza dos alunos, a materialidade precária das escolas, a desvalorização dos professores em termos de salário, carreira e condições de trabalho apenas são tangenciadas ou mesmo negligenciadas por não se considerar a formação escolar efetivamente como uma formação cidadã, e sim uma padronização que interessa às organizações internacionais e ao setor empresarial do País, submetido à manutenção do atual desenvolvimento do capitalismo mundial.

A Base Nacional Comum Curricular (BNCC), que teve recente aprovação por um submisso Conselho Nacional de Educação ${ }^{1}$, atendendo à terceira versão encaminhada pelo Ministério da Educação, mereceu contundentes críticas de entidades defensoras da educação pública, laica e gratuita. A falta de transparência nos debates que antecederam sua aprovação permitiu que o seu conteúdo acolhesse sobretudo interesses dos institutos empresariais, do mercado editorial e de movimentos retrógrados e religiosos. A ênfase às habilidades socioemocionais enfatizadas no texto sugere um pressuposto de que a vida não se resolve no rigor da luta pelos direitos sociais, mas sim com empreendedorismo. Esta base tende a ser aprovada pelo Congresso Nacional, tornar-se lei que alterará o PNE e a LDB/1996 em vigor, em mais um triste episódio de subserviência à agenda imposta pelo governo golpista. O texto padroniza os conteúdos para todas as escolas deste imenso país, desprezando as diversidades locais e regionais, ameaçando o 
pluralismo de ideias e de concepções político-pedagógicas, o direito às diferenças étnicas, raciais e de gênero, experiências em espaços não escolares, entre outros aspectos.

A concepção que se torna cada vez mais hegemônica no atual contexto está presente também na "Nova Política Nacional de Formação de Professores", conforme proposta apresentada em power point pelo MEC em outubro de 2017 - alinhada à BNCC recém aprovada pelo CFE, e à nova Lei do Ensino Médio já em implantação.

Historicamente, o privado foi parâmetro de organização da escola pública, o que pode ser exemplificado pelas influências já exaustivamente analisadas do Fordismo na educação: hierarquia, divisão social do trabalho, especialização, formas de controle, entre outras. Nosso país, no entanto, viveu processo recente de democratização. Lutamos por outra forma de organização da escola com princípios democráticos e críticos à teoria do capital humano e suas concepções gerenciais de organização. Avançamos alguns passos no sentido de democratização da educação e da sociedade no período recente, pós-ditadura, em que materializamos na legislação uma série de direitos, tais como a ampliação da obrigatoriedade escolar, do atendimento às diferenças culturais, sexuais, étnicas. Mas, em um processo de correlação de forças, também o setor privado se organizou para disputar tanto os fundos públicos como o conteúdo desta educação, de forma que temos hoje projetos de educação em disputa, vinculados aos projetos de sociedade em confronto.

A privatização não pode mais ser vista como uma simples ameaça ou como uma abstração. Cada vez mais precisamos ficar atentos, no seu processo de ampliação, aos sujeitos individuais ou coletivos que a mobilizam na educação. Avanços conquistados correm risco de um retrocesso pragmático no qual o mercado justifica a sua atuação no público para formar um sujeito instrumental à reestruturação produtiva, necessária ao desenvolvimento competitivo em nível internacional. Vivenciamos hoje, além do crescimento do setor empresarial disputando o conteúdo da educação, também o do setor neoconservador, que tem coagido professores e vem tentando imprimir a censura, anulando os passos que foram dados para uma educação mais democrática e menos discriminatória. É um processo de correlação de forças que não ocorre por acaso e que está cada vez mais dando direção para a política pública. Lutamos por processos democráticos e de justiça social na educação, e quanto mais avançamos neste caminho, mais o capital se organiza para retomar o seu papel na educação.

Significativas análises e informações constam deste Dossiê que apresentamos à comunidade educacional. Convidamos algumas autorias estrangeiras e brasileiras para analisar o processo focalizado. Outros artigos, submetidos em demanda contínua, apresentados por pesquisadores que estudam o tema, também foram contemplados por evidenciarem e analisarem formas de privatização da e na educação.

Iniciamos com o texto de Glenn Rikowski, Privatização em educação e formas da mercadoria (Privatisation in Education and Commodity Forms), o qual nos foi enviado em inglês, 
e traduzido para a sua publicação. Este provocativo artigo faz uma profunda análise que abre novas perspectivas para a compreensão dos trabalhos que se seguem. $\mathrm{O}$ autor destaca, com base em Marx, a necessidade de ter como central na temática do Dossiê o entendimento de que é a produção social da força de trabalho para o sistema capitalista que está em jogo e que mobiliza o processo de privatização da e na educação, que hoje se desenvolve globalmente.

O artigo de Vera Peroni, Maria Raquel Caetano e Paula de Lima, que dá continuidade ao Dossiê, tematiza Reformas educacionais de hoje: as implicações para a democracia. Seu conteúdo retrata a atuação de sujeitos vinculados ao setor privado mercantil na direção da política educacional atual, evidenciando especificamente sua atuação na elaboração da Base Nacional Comum Curricular(BNCC), na reforma do Ensino Médio e no programa Escola sem Partido (ESP).

O texto apresentado por Tereza Adrião e Teise Garcia, Educação a domicílio: o mercado bate à sua porta, analisa a relação entre a educação domiciliar e a privatização da oferta da educação, em sua etapa obrigatória. Identifica essa prática com a tendência de ampliação de políticas de escolha parental, que tendem a aprofundar desigualdades educativas e a subordinar a educação básica a interesses privados. Caracteriza também, o papel do Grupo Pearson, importante instituição do mercado educacional mundial, que mantém um setor especificamente voltado para a educação doméstica.

Os três artigos que se seguem dizem respeito à formação dos professores para a educação básica. Desnecessário frisar a importância de analisar o que ocorre no atual contexto com esta formação pelo seu papel estratégico para o desenvolvimento - ou a resistência - das reformas em andamento. O artigo de Allan Kenji Seki, Artur Souza e Olinda Evangelista, A formação docente superior: hegemonia do capital no Brasil, apresenta a situação calamitosa vivida pelo País ao evidenciar, com base em microdados do Inep, que a formação de professores para a educação básica em nível superior encontra-se majoritariamente articulada a grandes instituições privadas, com forte concentração nos cursos a distância, demonstrando essencial subordinação desta formação com os objetivos do capital. Cristina Pulido Montes e Luis Miguel Lorente destacam a influência da cultura da performatividade na ação do professorado espanhol, impulsionada por mecanismos ocultos da privatização que assola seu país, no artigo Performatividad y gerencialismo en la Comunidad de Valencia (España): efectos de la privatización endógena en el profesorado. $\mathrm{O}$ estudo focaliza os novos modos de agir dos professores frente a determinados programas relacionados à privatização endógena espanhola. $O$ texto apresentado por Jaqueline Bittencourt e Maria Luz Perez, ambas originárias do Estado Plurinacional da Bolívia, dá visibilidade a um contraponto às duas situações anteriores ao relatar o processo de formação docente boliviano que enfatiza o público em detrimento do privado no artigo: O Novo rumo da formação docente em Bolívia. Um movimento diferente? Demonstram que, a 
partir da revolução cultural boliviana e com a promulgação da Constituição de 2009, a organização da formação docente sofreu importante transformação nesse país.

Fatima Antunes e Sofia Viseu, autoras portuguesas do artigo A cobertura mediática do debate público:governação e privatização da educação em Portugal, analisam o debate sobre os contratos de associação de escolas privadas ao sistema público, particularizando a cobertura mediática a respeito das condições em que tais contratos poderiam ser realizados.

A parceria público-privada, a ingerência de interesse privado na educação pública e sua regulamentação são objeto dos três artigos que se seguem. Em A Educação Básica brasileira e as novas relações entre o Estado e os empresários, Elma de Carvalho analisa a presença de empresários na formulação de políticas e na gestão da educação básica pública brasileira, reportando-se ao programa "Arranjos de Desenvolvimento da Educação" (ADE). Liane Vizzotto, Berenice Corcette e Sandra Pierozan apresentam no texto $O$ público e o privado para os serviços sociais, um estudo realizado sobre a regulação jurídica na relação público-privada, com o objetivo de analisar como as parcerias ocorrem no contexto dos serviços sociais, inclusive na educação. Ressaltam o crescimento dos instrumentos reguladores decorrente de leis criadas com esta finalidade de regular parcerias, inclusive nas políticas educacionais. Por sua vez, a forte ingerência sobre o processo de gestão democrática da escola pública é focalizada no artigo As parcerias público-privadas na educação: cerceando autonomia e gestão democrática, de autoria de Alexandre José Rossi , Juliana Lumertz e Daniela de Oliveira Pires, que analisa a parceria firmada entre um município do estado do Rio Grande do Sul e o Instituto Ayrton Senna (IAS).

A atuação dos think tanks como estratégia de setores da política e da economia para divulgação e formação de opinião é uma novidade em expansão no Brasil. Liane Bernardi , Fabiola Borowsky, Monique Montano e Maria Otília Susin, no artigo Os think tanks liberais no País: a Universidade Aberta de Porto Alegre apresentam um estudo sobre o seu conteúdo, sujeitos e rede de apoiadores, defensores das teorias liberais do capital humano e do empreendedorismo. Sua materialização é focalizada na criação de um think tank que atua como centro de formação de professores e outros profissionais na gestão pública em Porto Alegre.

A reforma do ensino médio é um exemplo candente de como o capital, por meio da privatização, vem atuando em rede para implementar sua agenda para a educação. Dois textos destacam esta temática, o artigo de José Arlen Beltrão e Celí Tafarell, A ofensiva dos reformadores empresariais e a resistência de quem defende a educação pública; e o de Vinicius Bezerra e Carla Zandavalli Maluf de Araújo, A reforma do ensino médio: privatização da política educacional. Ambos evidenciam estudos que convergem e se complementam sobre a participação do empresariado brasileiro nos encaminhamentos da atual reforma do ensino médio no Brasil.

ODossiê é complementado, na seção Documento deste número da Retratos da Escola, com um texto que expressa a posição da CNTE a respeito da privatização da educação a 
partir de uma investigação cujos resultados detectaram os movimentos privatistas que, silenciosamente, permeiam as ações políticas e governamentais no País. Ficou evidenciado que as ações privatistas contaminam as políticas públicas de gestão da educação pública em todos os níveis (federal, estaduais e municipais). O livro Privatização e Mercantilização da Educação Básica no Brasil, ${ }^{2}$ recentemente lançado pela CNTE em conjunto com a UNB (julho de 2017), aborda as contradições do financiamento público educacional, especialmente após a aprovação da EC 59, que ampliou a obrigatoriedade do ensino para 4 a 17 anos, demonstrando que essa conquista social, que situa o Brasil entre as nações que mais asseguram o ensino obrigatório no mundo, despertou ainda mais o apetite privado em todas as etapas da educação básica.

\section{Notas}

1 À exceção de três guerreiras representantes das entidades docentes...

2 Consultado em 23/11/17. Disponível em: http://www.cnte.org.br/images/stories/publicacoes/privatizacao_ mercantilizacao_educacao_basica_brasil.pdf 